\author{
Marquette University \\ e-Publications@Marquette
}

College of Nursing Faculty Research and

Publications

Nursing, College of

$1-2021$

\title{
Youth and Parent Health-Related Quality of Life and Association With Glycemic Outcomes in Preadolescents and Adolescents With Type 1 Diabetes
}

Joan P. Totka

Marquette University, Joan.totka@marquette.edu

Julia A. Snethen

University of Wisconsin-Milwaukee

Elizabeth D. Cox

University of Wisconsin - Madison

Follow this and additional works at: https://epublications.marquette.edu/nursing_fac

Part of the Nursing Commons

\section{Recommended Citation}

Totka, Joan P.; Snethen, Julia A.; and Cox, Elizabeth D., "Youth and Parent Health-Related Quality of Life and Association With Glycemic Outcomes in Preadolescents and Adolescents With Type 1 Diabetes" (2021). College of Nursing Faculty Research and Publications. 821.

https://epublications.marquette.edu/nursing_fac/821 
Marquette University

e-Publications@Marquette

\section{Nursing Faculty Research and Publications/College of Nursing}

This paper is NOT THE PUBLISHED VERSION; but the author's final, peer-reviewed manuscript. The published version may be accessed by following the link in the citation below.

Journal of Pediatric Health Care, Vol. 35, No. 1 (January/February 2021): 64-73. DOI. This article is (C) Elsevier and permission has been granted for this version to appear in e-Publications@Marquette. Elsevier does not grant permission for this article to be further copied/distributed or hosted elsewhere without express permission from Elsevier.

\section{Youth and Parent Health-Related Quality of Life and Association with Glycemic Outcomes in Preadolescents and Adolescents With Type 1 Diabetes}

Joan P. Totka Joint Clinical Assistant Professor, College of Nursing, Marquette University, Milwaukee, WI Department of Nursing Research, Children's Wisconsin-Milwaukee Hospital, Milwaukee, WI Julia A. Snethen Professor and PhD Program Director, College of Nursing, University of Wisconsin-Milwaukee, Milwaukee, WI

Elizabeth D. Cox Professor, Division of General Pediatrics and Adolescent Medicine, Departments of Pediatrics and Population Health Sciences, School of Medicine and Public Health, University of Wisconsin-Madison, Madison, WI 


\begin{abstract}
Introduction

We explored differences in Health-Related Quality of Life (HRQOL) and the youth's glycosylated hemoglobin (A1C) of preadolescent and adolescent youths with type 1 diabetes (T1D) by individual (age, sex, race) and family (socioeconomic status) factors, and associations between youths' HRQOL, their parents' HRQOL, and youth's A1c.
\end{abstract}

\title{
Method
}

Correlational secondary analysis of baseline data from a randomized controlled trial testing a developmental intervention for youths with T1D and their parents from two diabetes clinics.

\section{Results}

Better adolescent HRQOL was associated with better glycemic control. Better preadolescent HRQOL was associated with better parent HRQOL. Non-White adolescents had worse HRQOL than White adolescents; whereas Non-White preadolescents had worse glycemic control than White preadolescents.

\section{Discussion}

Addressing HRQOL may promote better glycemic control in adolescents with T1D. For preadolescents with T1D, parent HRQOL support may impact preadolescent HRQOL and improve glycemic control moving into adolescence. Further study is warranted for non-White youths with T1D HRQOL and A1C outcomes.

\section{KEY WORDS}

Type 1 diabetes, quality of life, glycemic control, family nursing, race

\section{INTRODUCTION}

The risk of type 1 diabetes (T1D) in youths has been rising steadily since 2002 in White, Black, and Hispanic youths, despite attempts to prevent, delay, or understand its etiology (Chiang et al., 2018). This rise reflects a $21 \%$ overall increase in prevalence, and an adjusted risk for developing T1D of 1.4\% per year in the United States (Chiang et al., 2018). There are an estimated 98,200 youths aged less than 15 years who develop T1D worldwide, and it is estimated that the 600,900 youths aged less than 15 years will increase to 1.11 million in the next 20 years (Patterson et al., 2019). Sadly, this does not include children diagnosed in less developed countries in which a lack of access to insulin results in high case mortality (Patterson et al., 2019). Although there is a lower prevalence of T1D in Black youths compared with White or Hispanic youths, the overall glycemic control of Black youths is significantly and clinically worse than the glycemic control of either White or Hispanic youths (Foster et al., 2019; Willi et al., 2015).

Unfortunately, in the United States, most youths with T1D do not meet goals for glycemic control. Foster et al. (2019) identified that only 17\% of 14,593 youths with T1D in the United States met the national guidelines of a glycemic control that is reflected in a glycosylated hemoglobin (A1c) blood test of less than $7.5 \%(58.5 \mathrm{mmol} / \mathrm{mol})$. It should be noted that as of the 2018 international guidelines, that goal was decreased to less than $7.0 \%(53 \mathrm{mmol} / \mathrm{mol})$ for those with access to 
comprehensive care (Mayer-Davis et al., 2018). Furthermore, 40\% of youths with T1D have A1c tests greater than $9 \%$ (75 mmol/mol), which is considered poor glycemic control (Chiang, Kirkman, Laffel, Peters, \& Type 1 Diabetes Sourcebook Authors, 2014; Wood et al., 2013). Poor glycemic control contributes to acute short-term health outcomes (severe hypoglycemia, diabetic ketoacidosis; Foster et al., 2019) and long-term complications (blindness, kidney failure, amputations; Jacobson et al., 2013). Yearly per-child cost for a youth in the United States with T1D is estimated at $\$ 6,702.30$ higher than for a youth without T1D (Miller et al., 2016).

Health-related quality of life (HRQOL) is a measure of an individual's well-being with respect to their physical health, general health status, worries about health, and the impact of a specific health condition on physical, social, and emotional functioning (Hilliard et al., 2020). Anderson et al.

(2017) found an inverse relationship between HRQOL and glycemic control as measured by A1c, which suggests its importance as an outcome measure concerning youths with T1D. Guidelines from the American Diabetes Association and International Society of Pediatric and Adolescent Diabetes suggest that HRQOL is an important parameter in the assessment and care of youths with T1D (American Diabetes Association, 2020; Delamater et al., 2018). However, the assessment of HRQOL is rarely part of routine diabetes clinical practice (Delamater et al., 2018). This may be due, in part, to provider perceptions of the time needed for families to complete the measures and the difficulty in interpreting and understanding how to use and/or apply these measures in a clinical setting (Myrvik et al., 2014).

Psychological support is necessary to promote effective coping and improved glycemic control, which in turn can lead to improved quality of life (Pihoker et al., 2018). Using patient-reported outcome measures, such as HRQOL, supports patient-centered care and must be further studied and standardized in the clinical setting (Agiostratidou et al., 2017). Parent-proxy HRQOL has frequently been used in research to measure HRQOL of youths but is not as accurate as self-report of youths and adolescents (Yi-Frazier et al., 2016).

Assessing the HRQOL of parents of youths with chronic illness in research is emerging as a way to assess and support the whole family of a youth with chronic illness (AlBuhairan et al., 2016; Grey, Jaser, Whittemore, Jeon, \& Lindemann, 2011; Jönsson, Lundqvist, Tiberg, \& Hallström, 2015). WeissbergBenchell et al. (2009) found that family conflict related to diabetes and negative family communication were associated with lower youth $\mathrm{HRQOL}$, suggesting that interventions that target diabetes-specific family interactions would benefit youth HRQOL. Some studies have tested family interventions of youths with T1D that were successful in improving parent HRQOL, such as skill training, family behavioral therapy, and training targeting family identified barriers to care (Fiallo-Scharer et al., 2019; Grey et al., 2011; Kichler, Kaugars, Marik, Nabors, \& Alemzadeh, 2013).

There are significant physical and psychological differences in preadolescent and adolescent youths with T1D that could impact their health outcomes. Markowitz, Garvey and Laffel (2015) suggested that youths aged less than 12 years want more independence but are not developmentally or cognitively ready to care for their diabetes independently. This disparity results in families' needing to provide most of the diabetes care for preadolescents to adhere to the diabetes regimen (Markowitz et al., 2015). In contrast, youths aged more than 12 years are cognitively ready to transition gradually to providing most of their own care; however, most youths have glycemic control that deteriorates during adolescence (Hilliard, Wu, Rausch, Dolan, \& Hood, 2013b; Markowitz et al., 2015). Hilliard et al. 
(2013b) suggested that some of these factors are modifiable, and some are not. Adolescents have physical changes that cause insulin resistance (growth, hormonal shifts; Markowitz et al., 2015). Adolescents also have psychosocial changes that impact their self-management, such as needing independence, fitting in with friends, and higher risks for depression, to name a few (Iturralde, Weissberg-Benchell, \& Hood, 2017). Some of these developmental changes result in conflict with parents that may result in barriers to parental involvement in adolescent diabetes cares (Markowitz et al., 2015). Any of these factors could affect and/or lead to worse glycemic control (Chiang et al., 2018; Markowitz et al., 2015).

Developmentally appropriate versions of the HRQOL measures exist for youths aged 8-12 years (preadolescents) and youths aged 13-18 years (adolescents) with T1D. However, no studies were found between 2000 and 2019 that explored differences in factors associated with HRQOL between preadolescent and adolescent youths. Furthermore, no research was found that compared the HRQOL of youths with T1D and the HRQOL of their parents.

Most of the youths with T1D in the United States do not meet national and international care goals, and poor control of T1D affects youths' physical health, HRQOL, and costs of care. To better understand and support the developmental clinical outcomes of children with diabetes and their families, evidence is needed regarding the differences in individual and family factors and HRQOL and glycemic control of youths among different age groups. The availability of this evidence may assist in efforts to target interventions to improve glycemic control and HRQOL.

\section{Purpose of the Study}

The purpose of this study was to explore the differences in HRQOL and A1c of preadolescent and adolescent youths with T1D by individual (age, sex, race) and family (socioeconomic status [SES]) factors, and associations between youths' HRQOL, their parents' HRQOL, and youth's A1c.

\section{Individual and Family Self-Management Theory}

The selection of variables used in the design of this study was guided by the Individual and Family SelfManagement Theory (IFSMT; Ryan \& Sawin, 2009). The IFSMT emphasizes the context (conditionspecific, physical and social environment, and individual and family risk and preventive factors), processes, and proximal and distal outcomes of self-management in chronic illness (Ryan \& Sawin, 2009). For this study, the contextual factors of interest are individual (age, sex, race) and family (SES), with a primary focus on the developmental level of the child, defined in this study as preadolescent, (age 8-12 years) or adolescent (age 13-16 years). The outcome data of interest are HRQOL and glycemic control.

\section{Hypotheses}

We investigated the differences and associations of individual and family context factors with the outcomes of glycemic control and HRQOL scores in preadolescent and adolescent youths with T1D. Consistent with the IFSMT, we tested the following hypotheses.

1. There will be differences in the mean scores of glycemic control and HRQOL of preadolescents and adolescents related to individual and family factors (age, sex, race, and SES). 
2. HRQOL will be negatively correlated with glycemic control of preadolescents and adolescents; higher HRQOL will be associated with lower A1c.

3. HRQOL of preadolescents and adolescents and their parent's HRQOL will be positively correlated; higher youth HRQOL will be associated with higher parent HRQOL.

\section{METHODS}

\section{Design}

This study was a comparative and correlational secondary analysis of baseline data collected for the "Impact of Family-Centered Tailoring of Pediatric Diabetes Self-Management Resources" study (FialloScharer et al., 2019). The current study used a subset of baseline data from the primary study collected between September 2014 and May 2015.

The primary study evaluated the impact of developmentally appropriate, family-centered interventions (understanding and organizing care, motivation, and family interactions). The interventions were tailored to support family identified barriers to care. Youth glycemic control measured by A1c, youth HRQOL, and parent HRQOL were also collected. The developmental interventions tested in the primary study were effective in improving glycemic control in adolescents, but not preadolescents (FialloScharer et al., 2019).

The primary study was approved by the Institutional Review Board of the university, which was the Institutional Review Board of record. This secondary analysis was deemed nonhuman subject research by the university, because data were deidentified, and the researcher did not have access to the patient-identified primary data.

\section{Setting and Sample}

The diagnosis of the youths took place at least 1 year before the primary study, and both parents and children had to be willing to participate in the study. Youths were recruited from two pediatric academic diabetes centers in the Midwestern United States (see Table 1 for demographics of youths and parent participants). Exclusion criteria included the following: (1) cognitive or behavioral impairments that would hinder participation in a group intervention, (2) non-English speaking, and (3) less than 1 year after diagnosis with T1D. Eligible youths and their parents were approached to consider participation by their care team while attending routine visits for standard diabetes care. The goal of recruitment was 200 youth-parent dyads across both sites. Both youths and parents who expressed interest in participating were assented and/or consented to participate in the study by research coordinators. Youths were given age-appropriate assents.

TABLE 1. Sample characteristics

\begin{tabular}{|l|l|l|}
\hline Characteristics & $\boldsymbol{n}$ & $\mathbf{\%}$ \\
\hline Age & & \\
\hline Preadolescents, aged 8-12 years & 93 & 44.3 \\
\hline Adolescents, aged 13-16 years & 117 & 55.7 \\
\hline Sex & & \\
\hline Male & 106 & 50.5 \\
\hline Female & 104 & 49.5 \\
\hline
\end{tabular}




\begin{tabular}{|l|l|l|}
\hline White & 192 & 91.4 \\
\hline Preadolescent & 88 & 95 \\
\hline Adolescent & 104 & 89 \\
\hline Non-White & 18 & 8.6 \\
\hline Preadolescent & 5 & 5 \\
\hline Adolescent & 13 & 11 \\
\hline SES: Private insurance & 154 & 73.3 \\
\hline Preadolescent & 67 & 72 \\
\hline Adolescent & 87 & 74 \\
\hline SES: Public insurance & 56 & 26.7 \\
\hline Preadolescent & 26 & 28 \\
\hline Adolescent & 30 & 26 \\
\hline Parent characteristics & 210 & 100 \\
\hline Mother & 181 & 84.6 \\
\hline White & 188 & 87.9 \\
\hline Level of control & & \\
\hline Goal A1c < 7.5\% & $14(15)$ & $25(21)$ \\
\hline Moderate A1c 7.5\% to 8.5\% & $40(43)$ & $30(26)$ \\
\hline Poor A1c > 8.5\% & $39(42)$ & $62(53)$ \\
\hline
\end{tabular}

Note. SES, socioeconomic status. International Society of Pediatric and Adolescent Diabetes (ISPAD) target of less than 7.5 at the time of data collection.

Participants were youths aged 8-16 with T1D and their parent, guardian, and/or primary caretaker (parent) dyad. For the current study, we separated the data by age group: preadolescent youths aged 8-12 years $(n=93)$ and adolescent youths aged $13-16$ years $(n=117)$ to evaluate developmental differences and associations as outlined in the hypotheses. Baseline data that contained complete data on the variables of interest in the current study from the primary study sample were used to reveal associations among the study variables as they were observed in usual care conditions before involvement in the intervention.

\section{Measures}

Some baseline data from the primary study were collected via the iPad to enter into a secure research database automatically. If paper versions of measures were used, or if data was abstracted from the electronic health record (such as A1c), research assistants from the primary study hand-entered data into the secure database. A new deidentified data set and the codebook was created for this secondary analysis by the data manager of the primary study and provided to the first author of the current study.

\section{Individual and Family Context Variables}

Individual variables included age, which was categorized as preadolescent (age 8-12 years) and adolescent (age 13-16 years), sex (male, female), and race of the youth. Race was divided into two groups. Non-White participants (including Non-Hispanic ethnicity) comprised Black, mixed, and other races and represented $8.6 \%$ of total participants. White participants (including White-Hispanic ethnicity) represented the remaining $91.4 \%$ of total participants. The family variable was SES, which 
was measured using public and private insurance as a proxy. These demographic data were collected in the primary study database.

\section{A1c Test}

The A1c test represents overall glycemic control. This test is the standard for tracking and predicting risks of complications in patients with T1D based on the Diabetes Control and Complications Trial in 1993 (Sacks, 2012). For the primary study, A1c testing was standardized at both sites using a fingerstick blood sample and the DCA Vantage (Siemens Medical Solutions Diagnostics, Erlangen, Germany). This device meets the accepted performance criteria for A1c and exceeds some laboratory-based methods (Lenters-Westra \& Slingerland, 2014). A significant clinical difference in A1c test score results was identified as $0.5 \%$ (Little, Rohlfing, Sacks, \& National Glycohemoglobin Standardization Program (NGSP) Steering Committee, 2011). These data were abstracted from the electronic medical record by research assistants from the primary study and entered into the secure database.

\section{Pediatric Quality of Life Inventory Diabetes Module}

The 28-item Pediatric Quality of Life Inventory Diabetes Module (PedsQL-DM) was completed either by an electronic tablet or paper by youths in the study. The PedsQL-DM was designed to measure HRQOL dimensions tailored to pediatric diabetes (Varni, Burwinkle, \& Seid, 2005). These age-specific measures are developmentally appropriate, and the reliability and validity of these measures have been tested in preadolescent and adolescent youths with T1D. In the current analysis, the Cronbach alpha coefficients for preadolescents was $\alpha=0.87$, mean $=66.55$, standard deviation $(S D)=12.65$, and $\alpha=0.91$ for adolescents, mean $=65.91, \mathrm{SD}=12.58$. Hilliard et al. (2013a) identified the minimally important clinical difference of the score as 5.27 for youth reports for participants with T1D taking the PedsQL-DM.

\section{PedsQL Family Impact Module}

The PedsQL Family Impact Module was developed to address the family impact of pediatric chronic health conditions on the family (Varni, Sherman, Burwinkle, Dickinson, \& Dixon, 2004). The PedsQL Family Impact Module includes subscales; however, for this study, only the HRQOL portion was analyzed and compared. The HRQOL portion of the PedsQL-FIM consists of the first three subscales of the six subscales: (1) emotional functioning (5 items); (2) social functioning (4 items); (3) communication ( 3 items). In the current analysis, the Cronbach alpha was $\alpha=0.95$ for the parent HRQOL part of the PedsQL-FIM.

\section{Data analysis}

Youth and parent data were paired for the analysis using a linking code. All analyses of data were performed using SPSS version 24 within the secure research platform. Independent sample $t$ tests were used to determine differences in the outcome variables (A1C and HRQOL) between dichotomized context variables, with age, sex, race, and SES as the independent variables. Because of the uneven group sizes in analyses of differences by race group, we used Welch $t$ test that assumes unequal variance. Associations between context and outcome variables were analyzed using Pearson correlations $(r)$. Preliminary analyses were performed to ensure there was no violation of the assumptions of normality, linearity, and homoscedasticity of the continuous data. All the continuous variables met these assumptions except the A1c, which was negatively skewed. Hemoglobin A1c values 
were therefore log-transformed into a new variable named A1c Log (with a mean of 0.95 and SD of 0.08 [minimum of 0.76 , maximum of 1.15]) for use in the correlation calculations.

\section{RESULTS}

Characteristics are displayed in Table 1 . The sample consisted of $44.3 \%$ preadolescents and $55.5 \%$ adolescents with nearly equal numbers of males and females. The sample was predominantly White ( $n=192,91.4 \%$ ), with only $8.6 \%$ of the sample non-White (Black $=7$, multiracial $=7$, Other [Hawaiian and/or Pacific Islander, Native American, Asian] =4). Rates of public insurance (the SES indicator) were similar in preadolescents (28\%) and adolescents (26\%). The mean A1c of preadolescent youths was $8.77 \%(72.3 \mathrm{mmol} / \mathrm{mol}), \mathrm{SD}=1.52$, and was not clinically or statistically different from the mean A1c of the adolescent youths at $9.09 \%(75.8 \mathrm{mmol} / \mathrm{ml}), \mathrm{SD}=1.86$ (difference of 0.14$)$. In this sample, fewer preadolescents than adolescents met the American Diabetes Association guidelines of A1c less than $7.5 \%$ (58.5 mmol $/ \mathrm{mol}) 15 \%$ versus $21 \%$, respectively.

\section{Hypothesis 1}

Results for the difference in HRQOL and A1c between preadolescent and adolescent youths for each of the individual and family factors (age, sex, race, and SES) are displayed in Table 2. Race was the only individual factor where significant differences were detected for both HRQOL and A1c.

TABLE 2. Differences in preadolescent and adolescent PedsQL-DM scores and glycemic control by individual (age, sex, race) and family (SES)

\begin{tabular}{|l|l|l|l|l|l|}
\hline Factor & Outcome & Mean (SD) & & Test statistics & $\boldsymbol{p}$ value \\
\hline Age & PedsQL-DM & & & $t_{(208)}=0.367$ & .714 \\
\hline & Preadolescent & $66.55(12.65)$ & & & \\
\hline & Adolescent & $65.91(12.58)$ & & & \\
\hline & Glycemic control (A1c log) & & & $t_{(208)}=-1.210$ & .227 \\
\hline & Preadolescent & $0.94(0.07)$ & & & \\
\hline & Adolescent & $0.95(0.08)$ & & & \\
\hline Sex & PedQL-DM & Male & Female & & \\
\hline & Preadolescent & $65.99(12.62)$ & $67.08(12.79)$ & $t_{(91)}=-0.415$ & .679 \\
\hline & Adolescent & $68.06(11.95)$ & $63.56(12.95)$ & $t_{(115)}=1.950$ & .053 \\
\hline & Glycemic control (A1c log) & Male & Female & & \\
\hline & Preadolescent & $0.93(0.08)$ & $0.94(0.06)$ & $t_{(91)}=-0.418$ & .677 \\
\hline & Adolescent & $0.96(0.09)$ & $0.94(0.08)$ & $t_{(115)}=0.662$ & .509 \\
\hline Race & PedsQL-DM & White & Non-White & & \\
\hline & Preadolescent & $66.97(12.49)$ & $59.17(14.75)$ & $t_{(91)}=-1.350$ & .307 \\
\hline & Adolescent & $66.88(12.28)$ & $58.14(12.66)$ & $t_{(115)}=-2.410$ & .033 \\
\hline & Glycemic control (A1c log) & White & Non-White & & \\
\hline & Preadolescent & $0.93(0.063)$ & $1.05(0.09)$ & $t_{(91)}=4.070$ & .036 \\
\hline & Adolescent & $0.95(0.083)$ & $0.99(0.08)$ & $t_{(115)}=2.030$ & .059 \\
\hline SES & PedsQL-DM & Private insurance & Public insurance & & \\
\hline & Preadolescent & $67.80(12.03)$ & $63.31(13.85)$ & $t_{(91)}=1.550$ & .153 \\
\hline & Adolescent & $66.36(12.17)$ & $64.58(13.82)$ & $t_{(115)}=0.670$ & .534 \\
\hline & Glycemic control (A1c log) & Private insurance & Public insurance & & \\
\hline
\end{tabular}




\begin{tabular}{|l|l|l|l|l|l|}
\hline & Preadolescent & $0.93(0.06)$ & $0.96(0.08)$ & $t_{(91)}=-1.960$ & .058 \\
\hline & Adolescent & $0.94(0.08)$ & $0.97(0.09)$ & $t_{(115)}=-1.300$ & .225 \\
\hline
\end{tabular}

Note. PedsQL-DM, Pediatric Quality of Life Inventory Diabetes Module; SES, socioeconomic status; SD, standard deviation; A1c, glycosylated hemoglobin. Sample size of preadolescents $(n=93)$ and adolescents $(n=117)$ was the same for all variables.

Non-White preadolescents had worse glycemic control (higher A1c) than White preadolescents $(p=.03)$. The difference between White and non-White adolescents' HRQOL was statistically $(p=.03)$ and clinically significant, with a mean difference of 8.74 points, above the previously established minimally important clinical difference of 5.27 points (Hilliard, et al. 2013a). Mean HRQOL of nonWhite preadolescents was lower by 7.80 points than White preadolescents, a finding that is clinically but not statistically significant.

No other statistically significant differences were noted between preadolescents' and adolescents' HRQOL and A1c by age, sex, or SES. Male adolescents trended toward higher HRQOL than female adolescents $(p=.05)$, and preadolescents with private health insurance trended toward better glycemic control $(p=.06)$.

\section{Hypothesis 2}

Results of correlational analysis of the associations of HRQOL of preadolescents and adolescents and their glycemic control are displayed in Table 3. Adolescent HRQOL scores, but not preadolescent scores, were significantly negatively correlated $(r=-.30, p=.001)$ with their glycemic control; higher HRQOL was associated with lower A1c.

TABLE 3. Means and correlations of youth HRQOL with glycemic control and parent HRQOL

\begin{tabular}{|l|l|l|l|l|}
\hline Youth HRQOL and glycemic control & $\boldsymbol{n}$ & Mean (SD) & Correlation $(\boldsymbol{r})$ & $\boldsymbol{p}$ value \\
\hline Preadolescent PedsQL-DM & 93 & $66.55(12.65)$ & -.190 & .070 \\
\hline Preadolescent glycemic control (A1c log) & & $0.94(0.07)$ & & \\
\hline Adolescent PedsQL-DM & 117 & $65.57(12.58)$ & -.300 & .001 \\
\hline Adolescent glycemic control (A1c log) & & $0.95(0.08)$ & & \\
\hline Youth and parent HRQOL & $\boldsymbol{n}$ & Mean (SD) & Correlation ( $\boldsymbol{r})$ & $\boldsymbol{p}$ value \\
\hline Preadolescent PedsQL-DM & 93 & $66.55(12.65)$ & .333 & .001 \\
\hline Parent PedsQL-FIM & & $62.37(17.01)$ & & .181 \\
\hline Adolescent PedsQL-DM & 117 & $65.57(12.58)$ & .125 & \\
\hline Parent PedsQL-FIM & & $66.57(16.21)$ & & \\
\hline
\end{tabular}

Note. HRQOL, Health-Related Quality of Life; SD, standard deviation; PedsQL-DM, Pediatric Quality of Life Inventory Diabetes Module; A1c, glycosylated hemoglobin; PedsQL-FIM, Pediatric Quality of Life Inventory Family Impact Module.

\section{Hypothesis 3}

Results of correlational analyses of the associations of HRQOL of preadolescents and adolescents with the HRQOL of their parents are displayed in Table 3. Preadolescent HRQOL scores, but not adolescent scores, were significantly correlated $(r=.33, p=.001)$ with HRQOL scores of their parents. 


\section{DISCUSSION}

The primary findings of this study are that individual factors of youths with T1D are associated with glycemic control and HRQOL differently for preadolescents and adolescents. Non-White preadolescents had worse glycemic control than their White counterparts. However, only non-White adolescents had lower HRQOL than White adolescents. This contrast was also seen with the relationships between age group, $\mathrm{HRQOL}$, and A1c. Adolescent HRQOL was associated with their glycemic control, and preadolescent HRQOL was not associated with their glycemic control. Preadolescent HRQOL was associated with parent $\mathrm{HRQOL}$, but adolescent $\mathrm{HRQOL}$ was not. These findings demonstrate the complex relationships of age, race, HRQOL of both youths and parent, and glycemic control.

Non-White youth had worse A1c outcomes than White youths. However, they comprised only $8.6 \%$ of youths in this study; therefore, this difference must be interpreted with caution because of uneven group sizes. This difference in group sizes by race is true of most studies of T1D, as there is a higher incidence of T1D in non-Hispanic White youths than other races (Dabelea et al., 2014). The sample composition in this study aligns with the finding of Willi et al. (2015), who reported that although Black youths with T1D comprised $7 \%$ of a T1D registry of over 10,000 youths with T1D, those Black youths had significantly worse mean glycemic control as measured by A1c test. In addition, Willi et al. (2015) reported that both clinical outcomes and clinical management differed between the White and Black youths, even when controlled by SES.

It should be noted that Black youths with T1D and either high or low SES were less likely to be treated with insulin pumps or continuous glucose monitors than White or Hispanic youths with T1D with low SES (Willi et al., 2015). These findings may reflect a complex pattern of systemic and/or implicit bias affecting both clinical treatment and communication differences that Blair, Steiner, and Havranek (2011) reported as common and persistent. Race is a social determinant of health (Alegria et al., 2019; Trent, Dooley, \& Dougé et al., 2019) associated with both psychological and cardiovascular stress responses, which may lead to worse glycemic control (Sawyer, Major, Casad, Townsend, \& Mendes, 2012).

HRQOL scores were significantly lower in non-White adolescents than in White adolescents. Furthermore, the mean scores of non-White and White preadolescents were similar to those of the adolescent race groups, but the difference did not reach statistical significance, possibly because of uneven group size. One possible explanation is that non-White adolescents were more likely to have worse glycemic control, which was associated with lower HRQOL in adolescents but not in preadolescents. However, our inability to demonstrate racial and/or ethnic differences in HRQOL for preadolescents may simply be due to the smaller sample size in the preadolescent group. Alegria et al. (2019), in a longitudinal study of diverse youths, found a link between environment, discrimination, and internalizing symptoms such as stress and anxiety. Research is needed to explore these important health issues concerning race and health outcomes with a more balanced sample.

In preadolescents, glycemic control was not associated with HRQOL. This finding could be in part because the parents of preadolescents with T1D are usually in charge of most of the daily diabetes care. Developmentally, most youths with diabetes are ready to test their blood glucose when 
approximately 8 years old, give insulin injections at approximately 10 years old, and do not have the executive functions needed for complicated insulin to carbohydrate calculations until approximately 12 years old (Chien, Larson, Nakamura, \& Lin, 2007; Markowitz et al., 2015). Subsequently, preadolescents are not expected or able to drive the management of their diabetes care; therefore, preadolescents may not consider their diabetes outcomes as part of their concern or within their control. The gradual shift in care management from parents to youths as they move from later preadolescents to early adolescents begins the transition to the autonomy of diabetes care (Iturralde et al., 2017). Adolescents take on more and more of their diabetes care as they become older and, therefore, may feel more connected with the outcomes of their care (Schilling, Knafl, \& Grey, 2006).

In support of this interpretation of the findings, preadolescents' HRQOL was moderately associated with their parents' HRQOL, whereas adolescents' HRQOL was not associated with their parents' HRQOL. The moderate association we identified between the quality of life of preadolescents and their parents may be due to parents being more closely aligned, socially, and emotionally, with their preadolescents' lives and their diabetes management. In contrast, adolescent youths are more independent in performing their care and spend more time away from their families. A possible explanation of the lack of association between adolescent HRQOL and their parent's HRQOL may be that adolescents are less likely to share their emotions and relationships with their parents. Therefore, the parents of adolescents may not have that kind of information to incorporate into their quality of life evaluation. In chronic illness, the necessary parental involvement in daily care can lead to overprotection and overinvolvement of parents (Holmbeck et al., 2002). Overprotection and overinvolvement of parents may result in the relationships between adolescents with chronic illness and their parents to be more strongly affected by normal developmental shifts that occur during the transition from preadolescence to adolescence (Holmbeck et al., 2002).

The finding that parental HRQOL was differently associated with preadolescents and adolescents was a novel aspect of this study that may inform future intervention research. In addition, it may be important to consider the assessment of HRQOL of parents in clinical care, to identify potential psychosocial strengths and risks for support and referral. Assessment of parents may require more integrated referral avenues between pediatric and adult health care systems to support identified parent needs.

\section{Limitations}

The main disadvantage of using a secondary data set is that variables, subjects, and measurement tools were selected for the primary study (Hulley, Cummings, Browner, Grady, \& Newman, 2013; Polit \& Tatano, 2012). Other important variables to understanding the complexity of youth's diabetes experience were not available for this secondary analysis. Variables such as depression, anxiety, and youth and parent diabetes distress, as well as treatment variables (e.g., use of insulin pump or continuous glucose monitoring, location of treatment [urban, rural]), might help to explain the interrelationship of glycemic control and HRQOL.

Similar to most samples of youths with T1D, the current study had more White youths than Non-White youths, especially in the United States; the sample did not have much diversity in either the preadolescent or adolescent age groups (Dabelea et al., 2014). The percentage of White youths (91.4\%) was only slightly more than that of the White population (87.0\%) of the state in which the 
study was performed (United States Census Bureau, 2019). Although some of our data demonstrated statistically significant associations of outcomes with race similar to those identified in larger samples (Willi et al., 2015), they must be viewed with caution. Future studies with a more balanced sample are warranted. Moreover, the sample was not sufficiently large to determine differences by age groups within the non-White group.

SES was measured by private versus public insurance as a proxy measure. The use of other measures of SES with larger samples may produce different results in future studies. Therefore, our results should be considered cautiously within the constraints of the sample sizes and multiple analyses. Hemoglobin A1c and HRQOL were measured concurrently, and therefore the directional effect of one on the other cannot be determined, and no causal interpretation can be made from the findings. Future interventional studies may be able to ascertain if a directional relationship exists between those variables.

\section{Implications for Clinical Practice}

Glycemic control is an important aspect of outcomes in the care of youths with T1D. However, identifying meaningful outcomes beyond glycemic control is important in holistic, person- and familycentered care (Angiostatidou et al., 2017). This study highlights some differences among youths as they transition from preadolescence to adolescence, concerning associations between A1c and HRQOL and associations between youth quality of life and parent HRQOL.

Health care providers and clinical teams should consider including patient-reported outcome screening, such as the HRQOL, to examine the overall psychosocial health of youths and their families affected by T1D. Psychosocial screening of quality of life, depression, diabetes distress, and social determinants of health is recommended by national and international standards (ADA, 2020; Delamater et al., 2018). However, few pediatric diabetes practices incorporate these measures into their clinical care (ADA, 2020; Delamater et al., 2018).

Teams caring for youths with T1D often include nurses, social workers, and psychologists who are well suited to support the psychosocial health of youths with T1D and their families. As de Wit et al. (2010) demonstrated, the benefits of assessing HRQOL and addressing implications of HRQOL in adolescents were not sustained when the formal assessment was discontinued. Current work by Hilliard et al. (2020) to develop a brief clinically validated tool for both preadolescents and adolescents to assess HRQOL in the clinical setting is a promising addition. Although HRQOL is not the only parameter of interest associated with outcomes of self-management, it continues to be an important parameter to support overall health and well-being as well as the disease-specific outcome of glycemic control. Future work integrating patient-reported outcome measures seamlessly into the clinical workflow will be key for successful implementation of any patient-reported outcome measure (Hilliard et al., 2018; Myrvik et al., 2014).

Evidence-based behavioral interventions have had success in promoting diabetes management in children, adolescents, and families and should be tested in practice (Hilliard, Powell, \& Anderson, 2016). These interventions include coping skills training (Grey, Boland, Davidson, Li, \& Tamborlane, 2000; Grey et al, 2011), family interventions (Anderson, Brackett, Ho, \& Laffel, 1999; Wysocki et al., 2008), technology and mHealth interventions, and health care delivery system interventions (de Wit et 
al., 2010). Community-based multisystemic interventions that integrate behavioral health care for youths with T1D with chronically poor glycemic control may be an effective way to support care in pediatric diabetes clinics as well (Hilliard et al., 2016).

The results of this study suggest supporting the HRQOL of parents of preadolescents may impact both the parents' coping and management of the child's cares, as well as the preadolescent glycemic control. In adolescents with T1D, supporting their HRQOL may directly impact the coping and management of their diabetes care and result in improved glycemic control. Improved emotional and psychosocial health for those youths with poor glycemic control could result in fewer long-term complications and costs of care due to decreased hospitalizations and emergency room visits. In addition, the differences between preadolescent and adolescent relationships with their parents, as well as between their HRQOL and their outcomes of care, are developmentally plausible and warrant further investigation.

Differences in the glycemic control that we noted by race in our study may point to the need for education of the entire health care team on implicit bias, systemic bias, and perhaps the long-term effects of environment or trauma on patients and their families. By increasing team awareness of the potential for implicit bias or other effects of race as a social determinant, the team may be able to implement strategies that lead to increased communication and trust with all families.

\section{CONCLUSIONS}

The daily care required to manage T1D is complex and continuous for the youth's lifetime. Parent, youth, and family relationships are impacted by daily care demands. Care strategies must address individual and family factors to encompass a broader perspective beyond physical symptoms and laboratory tests. To improve physical and emotional care outcomes and reduce long-term complications and cost of T1D, research-based interventions to support increased quality of life of both youths and their parents should be considered as part of the standard care for families that are affected with T1D.

Non-White preadolescent youths with T1D may need special attention to address their increased risk for poor glycemic control. Addressing issues related to the adolescent quality of life is one strategy to promote better glycemic control and should be a standard component of adolescent diabetes care. For preadolescents, addressing issues that impact their parents' quality of life issues may positively impact the preadolescent's own quality of life, setting the stage for better glycemic control as they transition into adolescence. Further exploration of patients, their families, and their providers' perceptions associated with the use of patient-related outcome measures in routine care clinical settings will be important to assess their acceptance of using patient-reported outcome measures to improve care and collaboration in care and outcomes.

\section{REFERENCES}

Agiostratidou et al., 2017.

G. Agiostratidou, H. Anhalt, D. Ball, L. Blonde, E. Gourgari, K.N. Harriman, ..., S.A. Weinzimer. Standardizingclinically meaningful outcome measures beyond HbA1c for Type 1 diabetes: A consensus report of the American Association of Clinical Endocrinologists, the American 
Association of Diabetes Educators, the American Diabetes Association, the Endocrine Society, JDRF International, the Leona M. and Harry B. Helmsley Charitable Trust, the Pediatric Endocrine Society, and the T1D Exchange. Diabetes Care, 40 (2017), pp. 1622-1630

AlBuhairan et al., 2016. F. AlBuhairan, M. Nasim, A. Al Otaibi, N.A. Shaheen,, S. Al Jaser, I. Al Alwan.

Health related quality of life and family impact of type 1 diabetes among adolescents in Saudi Arabia. Diabetes research and clinical practice, 114 (2016), pp. 173-179

Alegria et al., 2019. M. Alegria, P.E. Shrout, G. Canino, K. Alvarez, Y. Wang, H. Bird, C. Duarte. The effect of minority status and social context on the development of depression and anxiety: a longitudinal study of Puerto Rican descent youth. World psychiatry: official journal of the World Psychiatric Association, 18 (3) (2019), pp. 298-307

American Diabetes Association 2020. American Diabetes Association [ADA]. 13. Children and adolescents: Standards of Medical Care in Diabetes-2020. Diabetes Care, 43 (Suppl 1) (2020), pp. S163-S182

Anderson et al., 1999. B.J. Anderson, J. Brackett, J. Ho, L.M. Laffel. An office-based intervention to maintain parent-adolescent teamwork in diabetes management. Impact on parent involvement, family conflict, and subsequent glycemic control. Diabetes Care, 22 (1999), pp. 713-721

Anderson et al., 2017.

B.J. Anderson, L.M. Laffel, C. Domenger, T. Danne, M. Phillip, C. Mazza, ..., C. Mathieu. Factors associated with diabetes-specific health-related quality of life in youth with type 1 diabetes: The global TEENs study. Diabetes Care, 40 (2017), pp. 1002-1009 Blair et al., 2011. I.V. Blair, J.F. Steiner, E.P. Havranek. Unconscious (implicit) bias and health disparities: Where do we go from here. Permanente Journal, 15 (2011), pp. 71-78 Chiang et al., 2018.

J.L. Chiang, D.M. Maahs, K.C. Garvey, K.K. Hood, L.M. Laffel, S.A. Weinzimer, ..., D. Schatz. Type 1 diabetes in children and adolescents: A position statement by the American Diabetes Association. Diabetes Care, 41 (2018), pp. 2026-2044

Chiang et al., 2014. J.L. Chiang, M.S. Kirkman, L.M. Laffel, A.L. Peters, Type 1 Diabetes Sourcebook

Authors. Type 1 diabetes through the life span: A position statement of the American

Diabetes Association. Diabetes Care, 37 (2014), pp. 2034-2054

Chien et al., 2007. SC Chien, E Larson, N Nakamura, SJ Lin. Self-care problems of adolescents with type

1 diabetes in southern Taiwan. Journal of Pediatric Nursing, 22 (5) (2007), pp. 404-409

Dabelea et al., 2014. D. Dabelea, E.J. Mayer-

Davis, S. Saydah, G. Imperatore, B. Linder, J. Divers, ..., SEARCH for Diabetes in Youth Study.

Prevalence of type 1 and type 2 diabetes among children and adolescents from 2001 to 2009. Journal of the American Medical Association, 311 (2014), pp. 1778-1786

de Wit et al., 2010. M. de Wit, H.A. Delemarre-van de

Waal, J.A. Bokma, K. Haasnoot, M.C. Houdijk, R.J. Gemke, F.J. Snoek. Follow-up results on monitoring and discussing health-related quality of life in adolescent diabetes care: Benefits do not sustain in routine practice. Pediatric Diabetes, 11 (2010), pp. 175-181

Delamater et al., 2018. A.M. Delamater, M. de

Wit, V. McDarby, J.A. Malik, M.E. Hilliard, E. Northam, C.L. Acerini. ISPAD Clinical Practice 
Consensus Guidelines 2018: Psychological care of children and adolescents with type 1 diabetes. Pediatric Diabetes, 19 (Suppl. 27) (2018), pp. 237-249

Fiallo-Scharer et al., 2019. R. Fiallo-

Scharer, M. Palta, B.A. Chewning, V. Rajamanickam, T. Wysocki, T.B. Wetterneck, E.D. Cox. Impact of family-centered tailoring of pediatric diabetes self-management resources.

Pediatric Diabetes, 20 (2019), pp. 1016-1024

Foster et al., 2019.

N.C. Foster, R.W. Beck, K.M. Miller, M.A. Clements, M.R. Rickels, L.A. DiMeglio, ..., S.K. Garg.

State of type 1 diabetes management and outcomes from the T1D exchange in 2016-2018.

Diabetes Technology and Therapeutics, 21 (2019), pp. 66-72

Grey et al., 2000. M. Grey, E.A. Boland, M. Davidson, J. Li, W.V. Tamborlane. Coping skills training for

youth with diabetes mellitus has long-lasting effects on metabolic control and quality of life. Journal of Pediatrics, 137 (2000), pp. 107-113

Grey et al., 2011. M. Grey, S.S. Jaser, R. Whittemore, S. Jeon, E. Lindemann. Coping skills training for parents of children with type 1 diabetes: 12-month outcomes. Nursing Research, 60 (2011), pp. $173-181$

Hilliard et al., 2018. M.E. Hilliard, M. De Wit, R.M. Wasserman, A.M. Butler, M. Evans, J. WeissbergBenchell, B.J. Anderson. Screening and support for emotional burdens of youth with type 1 diabetes: Strategies for diabetes care providers. Pediatric Diabetes, 19 (2018), pp. 534-543 Hilliard et al., 2013a.

M.E. Hilliard, J.M. Lawrence, A.C. Modi, A. Anderson, T. Crume, L.M. Dolan, ..., SEARCH for Diabetes in Youth Study Group. Identification of minimal clinically important difference scores of the PedsQL in children, adolescents, and young adults with type 1 and type $\mathbf{2}$ diabetes. Diabetes Care, 36 (2013), pp. 1891-1897

Hilliard et al., 2020. M.E. Hilliard, C.G. Minard, D.G. Marrero, M. de Wit, D. Thompson, S.N. DuBose, ..., B.J. Anderson. Assessing health-related quality of life in children and adolescents with diabetes: Development and psychometrics of the type 1 diabetes and life (T1DAL) measures. Journal of Pediatric Psychology, 45 (2020), pp. 328-339

Hilliard et al., 2016. M.E. Hilliard, P.W. Powell, B.J. Anderson. Evidence-based behavioral interventions to promote diabetes management in children, adolescents, and families. American Psychologist, 71 (2016), pp. 590-601

Hilliard et al., 2013b. M.E. Hilliard, Y.P. Wu, J. Rausch, L.M. Dolan, K.K. Hood. Predictors of deteriorations in diabetes management and control in adolescents with type 1 diabetes. Journal of Adolescent Health, 52 (2013), pp. 28-34

Holmbeck et al., 2002.

G.N. Holmbeck, S.Z. Johnson, K.E. Wills, W. McKernon, B. Rose, S. Erklin, T. Kemper. Observed and perceived parental overprotection in relation to psychosocial adjustment in preadolescents with a physical disability: The mediational role of behavioral autonomy. Journal of Consulting and Clinical Psychology, 70 (2002), pp. 96-110

Hulley et al., 2013. S.B. Hulley, S.R. Cummings, W.S. Browner, D.G. Grady, T.B. Newman. Designing clinical research (4th ed.). Jaypee Brothers, New Delhi, India (2013) 
Iturralde et al., 2017. E. Iturralde, J. Weissberg-Benchell, K.K. Hood. Avoidant coping and diabetesrelated distress: Pathways to adolescents' type 1 diabetes outcomes. Health Psychology, 36 (2017), pp. 236-244

Jacobson et al., 2013. A.M. Jacobson, B.H. Braffett, P.A. Cleary, R.A. GubitosiKlug, M.E. Larkin, DCCT/EDIC Research Group. The long-term effects of type 1 diabetes treatment and complications on health-related quality of life: A 23-year follow-up of the Diabetes Control and Complications/Epidemiology of Diabetes Interventions and Complications cohort. Diabetes Care, 36 (2013), pp. 3131-3138

Jönsson et al., 2015. L. Jönsson, P. Lundqvist, I. Tiberg, I. Hallström. Type 1 diabetes - Impact on children and parents at diagnosis and 1 year subsequent to the child's diagnosis. Scandinavian Journal of Caring Sciences, 29 (2015), pp. 126-135

Kichler et al., 2013. J.C. Kichler, A.S. Kaugars, P. Marik, L. Nabors, R. Alemzadeh. Effectiveness of groups for adolescents with type 1 diabetes mellitus and their parents. Families, Systems and Health, 31 (2013), pp. 280-293

Lenters-Westra and Slingerland, 2014. E. Lenters-Westra, R.J. Slingerland. Three of 7 hemoglobin A1c point-of-care instruments do not meet generally accepted analytical performance criteria. Clinical Chemistry, 60 (2014), pp. 1062-1072

Little et al., 2011. R.R. Little, C.L. Rohlfing, D.B. Sacks, National Glycohemoglobin Standardization Program (NGSP) Steering Committee. Status of hemoglobin A1c measurement and goals for improvement: From chaos to order for improving diabetes care. Clinical Chemistry, 57 (2011), pp. 205-214

Markowitz et al., 2015. J.T. Markowitz, K.C. Garvey, L.M. Laffel. Developmental changes in the roles of patients and families in type 1 diabetes management. Current Diabetes Reviews, 11 (2015), pp. 231-238

Mayer-Davis et al., 2018. E.J. MayerDavis, A.R. Kahkoska, C. Jefferies, D. Dabelea, N. Balde, C.X. Gong, ..., M.E. Craig. ISPAD Clinical Practice Consensus Guidelines 2018: Definition, epidemiology, and classification of diabetes in children and adolescents. Pediatric Diabetes, 19 (Suppl. 27) (2018), pp. 7-19

Miller et al., 2016. G.F. Miller, E. Coffield, Z. Leroy, R. Wallin. Prevalence and Costs of Five Chronic Conditions in Children. The Journal of School Nursing, 32 (5) (2016), pp. 357-364

Myrvik et al., 2014. M.P. Myrvik, L.M. Beverung, J.A. Panepinto, E.C. Igler, N. Englebert, K.M. Bingen. Integration of electronic patient-reported outcomes (ePROs) into pediatric clinic settings across hematology/oncology/bone marrow transplant. Clinical Practice in Pediatric Psychology, 2 (2014), pp. 39-49

Patterson et al., 2019.

C.C. Patterson, S. Karuranga, P. Salpea, P. Saeedi, G. Dahlquist, G. Soltesz, G.D. Ogle. Worldwide estimates of incidence, prevalence and mortality of type 1 diabetes in children and adolescents: Results from the International Diabetes Federation Diabetes Atlas, 9th edition. Diabetes Research and Clinical Practice, 157 (2019), Article 107842

Pihoker et al., 2018. C. Pihoker, G. Forsander, B. Fantahun, A. Virmani, S. Corathers, P. BenitezAguirre, ..., D.M. Maahs. ISPAD Clinical Practice Consensus Guidelines 2018: The delivery of ambulatory diabetes care to children and adolescents with diabetes. Pediatric Diabetes, 19 (Suppl. 27) (2018), pp. 84-104 
Polit and Tatano, 2012. D.F. Polit, C.B. Tatano. Nursing research: Generation and assessing evidence for nursing practice (9th ed.). Wolters Kluwer-Lippincott Williams \& Wilkins, Philadelphia (2012)

Ryan and Sawin, 2009. P. Ryan, K.J. Sawin. The Individual and Family Self-Management Theory: Background and perspectives on context, process, and outcomes. Nursing Outlook, 57 (2009), pp. 217-225 .e6

Sacks, 2012. D.B. Sacks. Measurement of hemoglobin A(1c): A new twist on the path to harmony. Diabetes Care, 35 (2012), pp. 2674-2680

Sawyer et al., 2012. P.J. Sawyer, B. Major, B.J. Casad, S.S. Townsend, W.B. Mendes. Discrimination and the stress response: Psychological and physiological consequences of anticipating prejudice in interethnic interactions. American Journal of Public Health, 102 (2012), pp. 1020-1026

Schilling et al., 2006. LS Schilling, KA Knafl, M Grey. Changing patterns of self-management in youth with type I diabetes. Journal of Pediatric Nursing, 21 (6) (2006), pp. 412-424

Trent et al., 2019. M. Trent, D.G. Dooley, J. Dougé, Section on Adolescent Health., Council on Community Pediatrics., \& Committee on Adolescence. The impact of racism on child and adolescent health. Pediatrics, 144 (2019), Article e20191765

United States Census Bureau 2019. United States Census Bureau. QuickFacts Wisconsin. (2019) Retrieved from https://www.census.gov/quickfacts/fact/table/WI/RHI125219\#RHI125219 Varni et al., 2005. J.W. Varni, T.M. Burwinkle, M. Seid. The PedsQL as a pediatric patient-reported outcome: Reliability and validity of the PedsQL Measurement Model in 25,000 children. Expert Review of Pharmacoeconomics and Outcomes Research, 5 (2005), pp. 705-719 Varni et al., 2004. J.W. Varni, S.A. Sherman, T.M. Burwinkle, P.E. Dickinson, P. Dixon. The PedsQL Family Impact Module: Preliminary reliability and validity. Health and Quality of Life Outcomes, 2 (2004), p. 55

Weissberg-Benchell et al., 2009. J. Weissberg-

Benchell, T. Nansel, G. Holmbeck, R. Chen, B. Anderson, T. Wysocki, ..., Steering Committee of the Family Management of Diabetes Study. Generic and diabetes-specific parent-child behaviors and quality of life among youth with type 1 diabetes. Journal of Pediatric Psychology, 34 (2009), pp. 977-988

Willi et al., 2015.

S.M. Willi, K.M. Miller, L.A. DiMeglio, G.J. Klingensmith, J.H. Simmons, W.V. Tamborlane, ..., T1D Exchange Clinic Network. Racial-ethnic disparities in management and outcomes among children with type 1 diabetes. Pediatrics, 135 (2015), pp. 424-434

Wood et al., 2013. J.R. Wood, K.M. Miller, D.M. Maahs, R.W. Beck, L.A. DiMeglio, I.M. Libman, ..., T1D Exchange Clinic Network. Most youth with type 1 diabetes in the T1D Exchange Clinic Registry do not meet American Diabetes Association or International Society for Pediatric and Adolescent Diabetes clinical guidelines. Diabetes Care, 36 (2013), pp. 2035-2037

Wysocki et al., 2008.

T. Wysocki, M.A. Harris, L.M. Buckloh, D. Mertlich, A.S. Lochrie, A. Taylor, ,.., N.H. White.

Randomized, controlled trial of Behavioral Family Systems Therapy for Diabetes:

Maintenance and generalization of effects on parent-adolescent communication. Behavior

Therapy, 39 (2008), pp. 33-46 
Yi-Frazier et al., 2016. J.P. Yi-

Frazier, M.E. Hilliard, N.F. Fino, M.J. Naughton, A.D. Liese, C.W. Hockett, ..., J.M. Lawrence. Whose quality of life is it anyway? Discrepancies between youth and parent health-related quality of life ratings in type 1 and type 2 diabetes. Quality of Life Research, 25 (2016), pp. $1113-1121$ 